\title{
Health care provider time in public primary care facilities in Lima, Peru: a cross- sectional time motion study
}

\author{
Hannah H. Leslie ${ }^{1}$, Denisse Laos ${ }^{2,3}$, Cesar Cárcamo², Ricardo Pérez-Cuevas ${ }^{4}$ and Patricia J. García ${ }^{2 *}$ (D)
}

\begin{abstract}
Background: In Peru, a majority of individuals bypass primary care facilities even for routine services. Efforts to strengthen primary care must be informed by understanding of current practice. We conducted a time motion assessment in primary care facilities in Lima with the goals of assessing the feasibility of this method in an urban health care setting in Latin America and of providing policy makers with empirical evidence on the use of health care provider time in primary care.
\end{abstract}

Methods: This cross-sectional continuous observation time motion study took place from July - September 2019. We used two-stage sampling to draw a sample of shifts for doctors, nurses, and midwives in primary health facilities and applied the Work Observation Method by Activity Timing tool to capture type and duration of provider activities over a 6-h shift. We summarized time spent on patient care, paper and electronic record-keeping, and non-work (personal and inactive) activities across provider cadres. Observations are weighted by inverse probability of selection.

Results: Two hundred seventy-five providers were sampled from 60 facilities; $20 \%$ could not be observed due to provider absence ( $2 \%$ schedule error, $8 \%$ schedule change, $10 \%$ failure to appear). One hundred seventy-four of the 220 identified providers consented (79.1\%) and were observed for a total of $898 \mathrm{~h}$ of provider time comprising 30, 312 unique tasks. Outpatient shifts included substantial time on patient interaction (110, 82, and 130 min for doctors, nurses, and midwives respectively) and on paper records (132, 97, and $141 \mathrm{~min}$ ) on average. Across all shifts, 1 in $6 \mathrm{~h}$ was spent inactive or on personal activities. Two thirds of midwives used computers compared to half of nurses and one third of doctors.

Conclusions: The time motion study is a feasible method to capture primary care operations in Latin American countries and inform health system strengthening. In the case of Lima, absenteeism undermines health worker availability in primary care facilities, and inactive time further erodes health workforce availability. Productive time is divided between patient-facing activities and a substantial burden of paper-based record keeping for clinical and administrative purposes. Electronic health records remain incompletely integrated within routine care, particularly beyond midwifery.

Keywords: Peru, Primary health care, Absenteeism, Time motion, Health information systems

\footnotetext{
* Correspondence: pattyjannet@gmail.com; Patricia.garcia@upch.pe

${ }^{2}$ School of Public Health, Universidad Peruana Cayetano Heredia, Lima, Peru

Full list of author information is available at the end of the article
}

(c) The Author(s). 2021 Open Access This article is licensed under a Creative Commons Attribution 4.0 International License, which permits use, sharing, adaptation, distribution and reproduction in any medium or format, as long as you give appropriate credit to the original author(s) and the source, provide a link to the Creative Commons licence, and indicate if changes were made. The images or other third party material in this article are included in the article's Creative Commons. licence, unless indicated otherwise in a credit line to the material. If material is not included in the article's Creative Commons licence and your intended use is not permitted by statutory regulation or exceeds the permitted use, you will need to obtain permission directly from the copyright holder. To view a copy of this licence, visit http://creativecommons.org/licenses/by/4.0/. The Creative Commons Public Domain Dedication waiver (http://creativecommons.org/publicdomain/zero/1.0/) applies to the data made available in this article, unless otherwise stated in a credit line to the data. 


\section{Background}

Efficiency - the provision of health services to maximize existing resources and minimize waste - is a key attribute of a high-quality health system [1-3]. From a system perspective, achieving efficiency requires delivery of the necessary services at the level most appropriate to provide quality care; within service delivery, efficiency depends upon the effective translation of available resources into value for patients [3]. Primary care is particularly critical to health system efficiency: primary care services that meet population needs and provide effective primary and secondary prevention result in better and more equitable population health benefits than higher cost specialty care $[4,5]$. Especially in resourceconstrained settings, the absence of trusted and highquality primary care has led to avertable morbidity and mortality and wasteful or even harmful overuse of specialist care $[2,6,7]$. Evidence on the delivery of primary care services to meet population health needs in the face of constrained resources is needed given the ongoing effects of the Covid-19 pandemic on both health services and health financing.

As in many Latin American countries, the health system in Peru faces a growing burden of noncommunicable diseases such as cardiovascular disease and diabetes, particularly in Lima, home to nearly 11 million people, even as total life expectancy continues to increase $[8,9]$. Primary care services are struggling to provide the continuity of care required to prevent and manage illness over time and are perceived to lack the resources and support required for high quality care [10]. Deficits and delays in primary care services result in the majority of the population avoiding routine preventive medical care [10], in frequent bypassing of primary care for pharmacies [11], and, for users of primary care in Lima, in an difficulty obtaining medications prescribed at the visit and dissatisfaction with long wait times $[12,13]$.

The health workforce is a key constraint in Peru, where there were 13 doctors per 10,000 individuals in 2016, one of the lowest levels in Latin America, and 24 nurse-midwives per 10,000 [14]. The public primary care system in particular has seen challenges in recruiting and retaining medical and nursing trainees [15]; the average health care provider in the public sector in Lima is 45 years old, 5 years older than the average provider in the private sector [16]. Since by law health care provider shifts are limited to $6 \mathrm{~h}$ and a maximum of $36 \mathrm{~h}$ per week, dual practice is common, with three in four private physicians near Lima working at least one other position, most commonly as a public provider [17]. Since 2013, the Ministry of Health (MOH) - which provides health services to over two thirds of the population [18] - has engaged in health system reform aiming to expand access to services and strengthen the inputs to health services as a pathway to universal health coverage [19, 20]. Increased financing and greater human resources for primary care were a key pillar of this effort [19]. The $\mathrm{MOH}$ has also looked to information technology to improve service delivery, although to date health information systems have been deployed in a largely fragmented manner: in 2017, the MOH had over 300 separate noninteroperable systems. Efforts to develop an electronic medical record (EMR) have been underway since 2010, starting with antenatal care [21,22] and expanding in 2016 to include additional modules for primary care services. Limited research to date has addressed the delivery of primary care services in light of these reforms.

Informing and evaluating health system performance requires measures that capture the productivity of primary care services, including provider use of time, effectiveness, and value to patients. While there are cross-national comparisons of patient experience in Latin America [23] and some evidence specific to Peru on patient satisfaction with care in public hospitals [24], little information is currently available on the productivity of the health workforce in primary care delivery, particularly in the context of expanding health technology systems. The dominant method for studying health care providers' use of time in health services is the time motion study, a method of direct observation [25]. Most such studies to date have been conducted in highincome countries [26]; there is a dearth of information available to assess and compare health care worker productivity and inform health system reforms in middleincome countries. The aims of the present study are to demonstrate the feasibility of a time motion study in urban primary care facilities and to describe the use of time by health care providers per shift in Lima, including the frequency of health information technology use within the daily practice of primary care.

\section{Methods}

The study protocol with full details is provided in the Supplemental Materials, as is the STROBE checklist for cross-sectional studies.

\section{Setting}

We conducted a continuous observation time motion assessment as a cross-sectional study at two tiers of primary care facilities in Lima, Peru. The $\mathrm{MOH}$ manages most of the public primary care facilities in the country; these facilities are divided into tiers from I-1 through I4, where I-4 is the highest capacity. In Supplemental material, Table S1 provides details on the tiers of primary care service delivery. We studied the more commonly used I-3 and I-4 facilities, which are staffed by a minimum of a doctor, nurse midwife, nurse technician, and laboratory technician. These facilities provide outpatient 
and preventive health services; they are required to have laboratory services. I-4 facilities may additionally include maternity wards and employ pediatricians and gynecologists. The 209 I-3 and I-4 facilities in Lima employed 3321 doctors, nurses, and midwifes at the time of the study.

\section{Sampling}

We conducted two-stage sampling, first at the facility level and then at the provider level. Facilities were randomly sampled from the database provided by the $\mathrm{MOH}$ within strata of facility tier (I-3, I-4). Facility directors at sampled facilities were approached for consent. Those consenting were asked to provide updated shift schedules for the subsequent week(s). One provider shift was selected at random for each type of provider (doctors, nurses and midwives) from these schedules. In cases where providers could not be found or declined to participate, a new shift was sampled at random for the following 7 days of enumerator availability. Neither providers nor facility directors were offered incentives to participate.

We calculated a sample size large enough to provide \pm $3 \%$ precision for the primary outcome of time spent on direct patient care. Drawing from existing literature on time-motion observations [25, 27-29], we estimated standard deviation in this outcome up to $10 \%$, which resulted in a target sample size of 54 providers per type. To account for potential non-response, particularly at small facilities with one or two providers per type, we sampled 60 facilities. We calculated sampling probability for each observation based on the number of providers of each type employed at the facility during the month the observation took place. Consideration of clustering by facility was not necessary as a single provider of each type was sampled per facility; analyses were conducted within provider types. We used administrative data available on all health care workers at $\mathrm{MOH}$ facilities in Lima to compare the sample achieved against the target population for potential selection bias [16]. We assessed overall feasibility of the time-motion study based on capacity to capture complete and usable data for all provider types from a representative sample of primary care facilities.

\section{Instrument}

We used the Work Observation Method by Activity Timing (WOMBAT, Australian Institute for Health Innovation, Macquarie University, North Ryde, NSW Australia) software program to assess provider time use [30]. This tool has been used in multiple countries and health system settings [31, 32], but not to our knowledge in Latin America. Using a tablet device, observers start a record for each task observed and classify it across three dimensions: activity, communication, and location. Tasks are ended once the task is complete, with time recorded exactly at start and end. For each dimension we defined major categories and subcategories based on existing literature on types of activities health professionals perform, adapted for the study context. Sub-categories were mutually exclusive; however, observers were able to designate interruptions and multitasking as they occurred.

\section{Data collection}

The team of 3 supervisors and 10 field workers was selected in June 2019; all team members had experience with primary health services as providers or trainees. Team members were trained for 5 days on research ethics, study procedures, and the use of the WOMBAT program and recognition of activity types using publicly available standardized patient cases. An additional facility was selected in the original sample to provide a pilot site; following consent from the facility director, 8 individual health care providers were selected, with each assigned 2 field workers for piloting. Based on the pilot, activity categories and sub-categories were refined to better reflect the provider tasks, including creating a separate template for doctors with a small number of clinical activities that nurses and midwives did not perform. The final tools are shown (in Spanish) in the Supplement, Figure S1 and S2.

The full cross-sectional study was conducted from July to September of 2019, with brief interruptions due to changes in health worker schedules for national holidays and a national health worker strike. During the week each facility was scheduled for assessment, study field workers visited the facilities unannounced $30 \mathrm{~min}$ prior to the scheduled start of the shifts and attempted to locate the selected provider for up to $2 \mathrm{~h}$ following the start of shift. If providers were located and consented to participate, the field worker was instructed to apply the observation protocol using WOMBAT until the scheduled end of the shift or the time the provider left the facility for non-work with no intention of returning. In the event the provider left the facility for work purposes (e.g. transfer patients in ambulance, home visits, etc.), observers requested permission to follow and if denied, waited for the provider to return until the end of the scheduled shift. If a provider or patient preferred for the observer not to be present during any clinical task, the observer waited nearby and recorded the activity as unobserved. Observers recorded the type of shift from the schedule. We grouped shifts into broad categories of outpatient (outpatient and triage), inpatient/urgent care (emergency, obstetric center, and inpatient urgent care) and other (administrative, community outreach, a mix of multiple responsibilities). 


\section{Measures}

We grouped activities from the time motion observation into work types based on previous use of the WOMBAT tool for time-motion observations [30]. Classifications (Table 1) were made by consensus among three authors and reviewed for consistency by the senior author PJG.

Periods without observation or with insufficient detail available (such as "Computer - read: Other) were classified as Other. Minutes from departure to the scheduled end of 6-h daytime shifts counted towards inactive time if providers departed for non-work activities before the shift concluded. Time from the scheduled start of shift to the beginning of observations was not eligible for analysis since providers had to provide consent prior to the observation starting.

We additionally defined 3 overarching activity classifications: any patient interaction, any documentation with paper, and any documentation with computers. These categories are not mutually exclusive as the activities above are. They are defined as:

- Patient care and communication: direct patient care and all time communicating with patient and family, even if other activities such as procedures or documentation were happening at the same time.
- Paper records: all activities conducted with paper records, including reading, and writing patient information, except for printing.

- Computerized records: all activities conducted with electronic resources, including reading, or writing electronic records, and printing.

We calculated proportion of time per activity out of actual minutes from the start of observation to end of observation or end of shift, whichever was later. We also defined a binary indicator of early departure as observations ending more than $20 \mathrm{~min}$ before scheduled end of daytime shifts.

We assessed the time motion data for data quality. First, we identified all individual tasks with duration over an hour as potentially erroneous (47 tasks within 40 providers). We reviewed the start and end time of these tasks, their timing within the observation, and the content and location of tasks within the pattern of provider activity for evidence that a task had been started or continued in error, such as overlapping tasks in different locations or with conflicting activities (e.g., no communication and communication with patient). We replaced as missing those tasks that met three criteria: they were the first or second task the observer recorded after beginning the observation, they lasted over $100 \mathrm{~min}$, and they

Table 1 Classifications of Activity Types from Time Motion Observation

\begin{tabular}{|c|c|c|}
\hline Activity type & Definition & Example codes \\
\hline Direct patient care & Procedures, communicating with a patient or family member & $\begin{array}{l}\text { Procedures: Physical exam / signs } \\
\text { Procedures: Clinical history }\end{array}$ \\
\hline Indirect patient care & $\begin{array}{l}\text { Reading patient history, ordering tests, washing hands, } \\
\text { cleaning up after procedure, retrieving information }\end{array}$ & $\begin{array}{l}\text { Paper-read: Clinical history } \\
\text { Computer-read: Clinical history } \\
\text { Search: Preparation of materials and supplies } \\
\text { Paper-write: Order tests }\end{array}$ \\
\hline Medication & $\begin{array}{l}\text { Finding orders; prescribing, preparing or administering } \\
\text { medication }\end{array}$ & $\begin{array}{l}\text { Search: Order } \\
\text { Phone: Prescription } \\
\text { Computer-read: Prescriptions } \\
\text { Paper-write: Prescription }\end{array}$ \\
\hline Documentation & Recording patient information on paper or computer & $\begin{array}{l}\text { Paper-write: Clinical history } \\
\text { Computer-write: Patient registries }\end{array}$ \\
\hline Professional communication & $\begin{array}{l}\text { Work-related discussions, including requesting consults, } \\
\text { presenting or handing over patients }\end{array}$ & $\begin{array}{l}\text { Computer-write: Referral / consult } \\
\text { Communication: Health workers, about work }\end{array}$ \\
\hline Administrative & $\begin{array}{l}\text { Staff meetings, administrative paperwork, coordination of } \\
\text { staff schedules or activities }\end{array}$ & $\begin{array}{l}\text { Paper-write: FUA } \\
\text { Paper-read: FUA } \\
\text { Search: Registry }\end{array}$ \\
\hline Transit & Movement between patients and between tasks & $\begin{array}{l}\text { Movement: Inside health facility } \\
\text { Movement: Outside health facility - home visit }\end{array}$ \\
\hline Education & Attending education sessions as teacher or student & $\begin{array}{l}\text { Paper-read: References (books or others) } \\
\text { Communication only: Listening to instruction }\end{array}$ \\
\hline Personal / social & Any social or personal activity or discussion & $\begin{array}{l}\text { Personal: Bathroom } \\
\text { Phone: Applications - personal } \\
\text { Personal: Leisure time }\end{array}$ \\
\hline Inactive & $\begin{array}{l}\text { No activity, including time from departure to end of shift } \\
\text { for providers leaving early }\end{array}$ & Other: Inactivity \\
\hline
\end{tabular}


overlapped with at least one task that conflicted in content or location.

\section{Analysis}

We report descriptive statistics of the health facilities and individual providers selected for participation and those ultimately enrolled in the study. Differences between participating and non-participating providers were assessed using the Chi Square test for categorical data and the Kruskal-Wallis test for differences in distribution for continuous variables.

We calculated sampling weights as the inverse probability of selection, scaled to sum to the observed number of providers per cadre. Analysis accounts for stratified sampling and probability weights. We present descriptive statistics of the total observations, including duration, raw number of tasks observed, and proportion of providers departing early.

We summarized the number of providers performing each category of activity and the mean minutes spent per activity by provider cadre and shift type (outpatient, inpatient/urgent, other). We tested the significance of differences in activities by shift type using design-based $F$ tests for proportion of providers performing the activity and linear regression for time per activity in order to incorporate sample strata and weights. Although we did not capture time spent by unique patient in the observations, we calculated and plotted time spent consecutively on patient-facing activities as an approximation of time per patient. We calculated the proportion of time spent on individual activities and summarized these graphically by provider cadre. We quantified time spent transcribing records as an indication of potential inefficiencies in health facility operation. Finally, we compared the time spent on direct patient care and the time spent on documentation for providers observed to use computers at all and those not observed using computers using linear regression. Raw data were exported to comma delimited files; analysis was performed using Stata 16.0 (Stata Corp, College Station, Texas).

\section{Results}

\section{Study sample}

Of the initial sample of 60 health facilities (40 I-3, 20 I4 ), one was excluded due to provision of mental health services only and one declined to participate. Two replacement facilities were sampled. A total of 275 providers were sampled for the study. Comparison to administrative data on all providers in the population (Supplement, Table S2) suggests composition of the sample was generally similar to the underlying population on characteristics such as age (sample average 46 years, population 49), contract type (sample $71 \%$ permanent, population $83 \%$ ), and facility tier (sample $36 \%$ from I-4 facilities, population $40 \%$ I-4 facilities). As in the population data, nearly all nurses (93\% in sample, $96 \%$ in population) and midwives (100\% in sample, $96 \%$ in population) are female, while the split for doctors is closer to even $(53 \%$ female in sample, $42 \%$ in population).

Provider characteristics by participation status are shown in Table 2. Of 275 sampled shifts in primary care facilities, 55 (20\%) could not be observed: in 6 cases, the named provider did not work at that health facility, in 21 the provider had switched shifts since the weekly schedule was released, and in 28 cases the provider did not show up for a scheduled shift (unplanned absenteeism [33]). There were no statistically significant differences between these 55 cases and the 220 providers identified based on the demographics and contract information provided by the $\mathrm{MOH}$.

Of the 220 providers approached for participation, 174 (79.1\%) consented and were observed for the duration of the shift: 59 doctors, 58 nurses, and 57 midwives. Among those found, those with permanent positions were more likely to decline consent (40 of 151, 26.5\%) than fixed term employees (5 of $35,14.3 \%$ ) and employees on short-term flexible contracts (1 of $303.3 \%$ ), $p<0.05$. Those consenting were younger than those declining to participate (mean 44.9 years for consented individuals vs. 51.0 years for those declining to participate, $\mathrm{p}<0.05$ ).

\section{Time motion observations}

A total of $898 \mathrm{~h}$ of provider time were observed, comprising 30,312 unique tasks; 22 tasks for 20 unique providers were replaced as missing following data quality assessment. Observations lasted a median of $5.3 \mathrm{~h}$ (interquartile range [IQR] $4.7-5.7 \mathrm{~h}$ ). The median number of tasks observed per shift was 148 for nurses, 163 for midwives, and 187 for doctors. Figure S3 in the Supplement depicts the observations from starting minute to ending minute, with I-3 health facilities observations $(N=116)$ in Figure S3A and I4 $(N=58)$ in Figure S3B. Scheduled shift start times are shown as red lines. Eighteen percent of daytime shifts ended more than $20 \mathrm{~min}$ before the scheduled end. Early departures were more common in I-3 facilities than I-4 facilities, particularly for morning shifts $(50 \%$ of I- 3 shifts vs. $1.5 \%$ of I-4 shifts, designbased $\mathrm{F}$ test $p<0.05$, compared to $27 \%$ of I-3 shifts and $13 \%$ of I- 4 shifts with early departures in afternoons, $p=$ 0.34 ). Early departures did not differ significantly by provider type or form of contract.

\section{Provider activities}

Table 3 presents the frequency and duration of overall activities by type of shift and provider cadre. For all cadres, the majority of shifts observed were of 
Table 2 Characteristics of providers sampled for observation (unweighted $N=275$ )

\begin{tabular}{|c|c|c|c|c|}
\hline & $\begin{array}{l}\text { Not found } \\
\left(n_{1}=55\right)\end{array}$ & $\begin{array}{l}\text { Refused/with-drew consent } \\
\left.n_{2}=46\right)\end{array}$ & $\begin{array}{l}\text { Consented and observed } \\
\left(n_{3}=174\right)\end{array}$ & $\begin{array}{l}\text { Total } \\
(n=275)\end{array}$ \\
\hline & Mean (SD) & Mean (SD) & Mean (SD) & Mean (SD) \\
\hline Age (years) & $45.7(9.4)$ & $51.0(9.7)$ & $44.9(10.5)$ & $46.1(10.4)$ \\
\hline \multirow[t]{2}{*}{ Years worked in health center } & $9.7(8.7)$ & $14.3(10.0)$ & $12.2(10.3)$ & $12.1(10.0)$ \\
\hline & n (col. \%) & n (col. \%) & n (col. \%) & n (col. \%) \\
\hline \multicolumn{5}{|l|}{ Facility tier } \\
\hline $1-3$ & $34(62 \%)$ & $25(54 \%)$ & $116(67 \%)$ & $175(64 \%)$ \\
\hline $1-4$ & $21(38 \%)$ & $21(46 \%)$ & $58(33 \%)$ & $100(36 \%)$ \\
\hline \multicolumn{5}{|l|}{ Provider type } \\
\hline Doctor & 19 (35\%) & $17(37 \%)$ & $59(34 \%)$ & $95(35 \%)$ \\
\hline Nurse & $20(36 \%)$ & $14(30 \%)$ & $58(33 \%)$ & $92(33 \%)$ \\
\hline Midwife & $16(29 \%)$ & $15(33 \%)$ & $57(33 \%)$ & $88(32 \%)$ \\
\hline \multicolumn{5}{|l|}{ Gender } \\
\hline Male & $10(19 \%)$ & $10(22 \%)$ & $29(17 \%)$ & $49(18 \%)$ \\
\hline Female & $44(81 \%)$ & $36(78 \%)$ & $139(83 \%)$ & $219(82 \%)$ \\
\hline \multicolumn{5}{|l|}{ Type of contract } \\
\hline Fixed term & $8(15 \%)$ & $5(11 \%)$ & $30(18 \%)$ & $43(16 \%)$ \\
\hline Permanent & $41(76 \%)$ & $40(87 \%)$ & $111(65 \%)$ & 192 (71\%) \\
\hline Short term & $5(9 \%)$ & $1(2 \%)$ & 29 (17\%) & 35 (13\%) \\
\hline
\end{tabular}

Table 3 Proportion of providers conducting activities and time spent on activities when observed

\begin{tabular}{|c|c|c|c|c|c|c|c|c|}
\hline & \multicolumn{2}{|l|}{ Outpatient } & \multicolumn{2}{|c|}{ Inpatient/urgent } & \multicolumn{2}{|l|}{ Other } & \multicolumn{2}{|l|}{ Total } \\
\hline & Frequency & $\begin{array}{l}\text { Duration } \\
\text { (minutes) if } \\
\text { done }\end{array}$ & Frequency & $\begin{array}{l}\text { Duration } \\
\text { (minutes) if } \\
\text { done }\end{array}$ & Frequency & $\begin{array}{l}\text { Duration } \\
\text { (minutes) if } \\
\text { done }\end{array}$ & Frequency & $\begin{array}{l}\text { Duration } \\
\text { (minutes) if } \\
\text { done }\end{array}$ \\
\hline & $\%$ & Mean (SD) & $\%$ & Mean (SD) & $\%$ & Mean (SD) & $\%$ & Mean (SD) \\
\hline A: Doctors & & $(N=49)$ & & $(N=7)$ & & $(N=3)$ & & $(N=59)$ \\
\hline Patient-facing care and communication & $100 \%$ & $110(39)$ & $100 \%$ & $45(39)$ & $9 \%$ & 3 & $95 \%$ & $97(47)$ \\
\hline Use of paper records & $98 \%$ & $132(51)$ & $100 \%$ & $64(48)$ & $100 \%$ & $46(34)$ & $99 \%$ & $115(58)$ \\
\hline Use of computerized records & $34 \%$ & $26(22)$ & $20 \%$ & 89 & $45 \%$ & $8(14)$ & $33 \%$ & $31(29)$ \\
\hline B: Nurses & & $(N=46)$ & & $(N=5)$ & & $(N=7)$ & & $(N=57)$ \\
\hline Patient-facing care and communication & $99 \%$ & $82(58)$ & $100 \%$ & $110(52)$ & $100 \%$ & $45(19)$ & $99 \%$ & $86(56)$ \\
\hline Use of paper records & $100 \%$ & $97(56)$ & $100 \%$ & $48(42)$ & $100 \%$ & $35(38)$ & $100 \%$ & $83(57)$ \\
\hline Use of computerized records & $49 \%$ & $35(42)$ & $62 \%$ & $18(23)$ & $52 \%$ & $44(41)$ & $52 \%$ & $32(38)$ \\
\hline C: Midwives & & $(N=46)$ & & $(N=8)$ & & $(N=3)$ & & $(N=57)$ \\
\hline Patient-facing care and communication & $97 \%$ & $130(79)$ & $100 \%$ & $93(74)$ & $100 \%$ & $81(38)$ & $98 \%$ & $115(77)$ \\
\hline Use of paper records & $100 \%$ & $141(62)$ & $100 \%$ & $55(22)$ & $100 \%$ & $114(35)$ & $100 \%$ & $110(65)$ \\
\hline Use of computerized records & $65 \%$ & $35(28)$ & $66 \%$ & $61(36)$ & $13 \%$ & 7 & $63 \%$ & $44(32)$ \\
\hline
\end{tabular}

Frequency is the proportion of providers observed to do each activity at least once; duration is mean minutes per activity among providers observed in that activity. Standard deviations not calculated for cells with a single observation

Outpatient includes consultations and triage. Hospitalization includes emergency, hospitalization, and obstetric center shifts. Other includes administrative work, home visits, and shifts with multiple classifications

Bold highlight indicates significant difference $(p<0.05)$ from outpatient shifts for that cadre 
individuals providing outpatient care, as expected at these primary care facilities. Patient interaction and use of paper records were nearly universal in this sample. Looking at patient-facing tasks as consecutive blocks, doctors on outpatient shifts spent an average of $3.3 \mathrm{~min}$ per patient interaction with 35 interactions per shift; inpatient doctors spent similar time but had only 15 interactions per shift. Nurses and midwives averaged 4 to 5 min per patient interaction and had 25 to 30 such interactions per shift (Supplement, Table S3). Overall, doctors performing outpatient shifts spent $110 \mathrm{~min}$ on average on patient-facing care and communication (30.6\% of a full shift) and $132 \mathrm{~min}$ on paper records (37\%), significantly more in both cases than did doctors on inpatient/urgent shifts (45 min of patient interaction [12.5\% of a shift] and $64 \mathrm{~min}$ [17.8\% of a shift] on paper records, respectively). Other doctor shifts involved very little patient contact and an average of $46 \mathrm{~min}$ on patient records [12.8\%].

Nurses spent an average of $82 \mathrm{~min}$ with patients per outpatient shift (22.8\%) and $97 \mathrm{~min}$ on paper records (26.9\%); inpatient shifts included $110 \mathrm{~min}(30.6 \%)$ with patients and $48 \mathrm{~min}$ on paper records (13.3\%), significantly less than outpatient shifts. Other shifts involved shorter durations of patient time and paper records.

Midwives on outpatient shifts spent the most time of any providers on patient-facing care $(130 \mathrm{~min}, 36.1 \%)$ and paper records (141 min, 39.2\%); inpatient shifts included 93 min of patient care (one-fourth of a shift) and 55 min with paper records (15.2\%), significantly less than outpatient. Unlike the other cadres, other shifts for midwives did not differ in terms of patient time or record time.

One third of doctors, half of nurses, and two thirds of midwives were observed to use computers. Among those using computers, midwives on inpatient shifts were observed to do so for more than an hour $(61 \mathrm{~min})$ per shift, as were the few doctors on inpatient shifts who used computers at all $(89 \mathrm{~min})$.

We included 10 mutually exclusive categories for this analysis of the proportion of shift spent in each category (Fig. 1; unobserved time is left blank). Approximately $15 \%$ of all provider time was spent on direct care (SD $7.8 \%$ for doctors to $11.5 \%$ for nurses), with $11 \%$ on indirect care for doctors and 14-15\% for midwives and nurses. Doctors spent almost as much time on documentation as they did on direct care, while nurses and midwives spent $20 \%$ of their shifts on documentation, more than they did on direct care. Administrative tasks took up the most time for doctors of the three provider types, a mean of $9 \%$ compared to $3 \%$ for nurses and $7 \%$ for midwives. Doctors spent over $20 \%$ of their time on either personal activities or inactive compared to $14 \%$ for nurses and midwives.

Detail on the specific tasks that providers conducted are shown in Table S4 in the Supplement. Time spent documenting patient care on patient records was the single most common activity on outpatient shifts, consuming between 11 and 19\% of provider time. This time is exclusive of administrative paperwork such as the

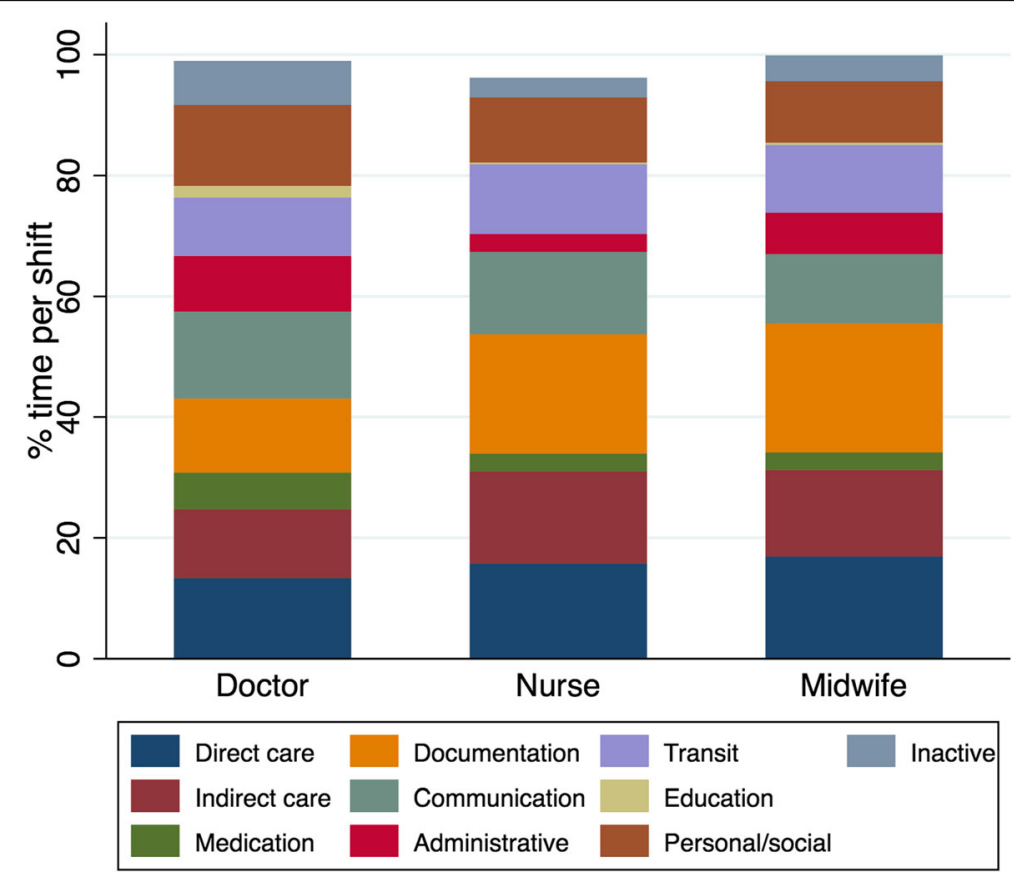

Fig. 1 Proportion of provider time spent by activity category 
FUA, which was a substantial use of time among doctors and nurses completing outpatient shifts as well. Shifts focused on inpatient care included more substantial personal time, between 16 and $40 \%$ of total time. While the median provider spent only $5-8 \%$ of each shift on any personal time, individual providers devoted half to two thirds of daytime shift hours to personal time, resulting in an average of $10-13 \%$ of each shift spent on personal time (Figure S4, Supplement). Taking into account personal time as well as inactive time, the average provider would lose nearly an entire shift $(6 \mathrm{~h})$ per 36 -h week of work to time spent not working.

\section{Time spent on documentation and health information}

Time documenting patient information on computers included transcription of previously written hard copies: of a total of $32.9 \mathrm{~h}$ of computerized documentation observed, $6.4 \mathrm{~h}$ were spent on transcription. Most of this effort was among midwives $(4 \mathrm{~h})$.

In the Supplement, Table S5 presents results on how providers who did and did not use computers spent time on shifts, excluding administrative shifts $(N=4)$. There were few significant differences in time spent on direct patient care or documentation across providers: doctors observed using computers spent $4 \%$ less time on direct care and 3\% more time on documentation, although these differences are not significant. Nurses' time in direct care or documentation did not differ by computer use. Midwives using computers spent $5 \%$ more time on direct care $(p<0.10)$ and $12 \%$ more time on documentation $(p<0.05)$ than those not using computers.

\section{Discussion}

\section{Summary of findings}

This study establishes the feasibility of performing a study of time use by primary care providers in Lima and can provide a template for similar studies in urban areas in Latin America to generate comparative data. Despite challenges such as a health provider strike during the study and frequent changes to scheduled shifts, nearly all facilities and most identified providers consented to participate. The field team was able to observe consenting providers for the duration of their shift and to obtain data with few evident errors. The findings demonstrate that at the time of this assessment in mid-2019, 10\% of scheduled shifts were unplanned absences; those present at the facilities spent on average $5 \mathrm{~h}$ of their 6 - $\mathrm{h}$ shifts working, with remaining time inactive or on personal activities. Providers of outpatient care spent most of their working time interacting with patients and on paper records, spending $1.5-2 \mathrm{~h}$ on each activity on average across cadres. Computer use was less frequent than paper record-keeping and was less common for doctors and nurses than for midwives, indicating that electronic medical records remained incompletely integrated into primary care practice in Lima, particularly outside of maternal health care services.

\section{Practice and policy implications}

Research in the early 2000s found that primary care providers were absent from clinics in Peru up to $25 \%$ of the time, with greater absenteeism among doctors and permanent (non-contract) providers [34], yet no clear policy action has been taken to address absenteeism. Previous research has found that over half of physicians in Peru report dual practice as of the early 2000s, with more recent research among surgeons underscoring the financial incentive to maintain a parallel private practice despite the corrosive effects on health care quality and equity $[35,36]$. In our study, 1 in 10 providers could not be found for a scheduled shift within a week of verifying the shift schedule (unplanned absenteeism), and nearly the same number had switched shifts after the schedule was finalized. Provider absence undermines the delivery of care and can erode trust in health services [37]; unplanned absences and frequent schedule switches may complicate efficient organization and delivery of services. Policies that have shown some effect in reducing absenteeism such as regulation of private sector dual practice and organizational improvements like clear communication, counseling of health care providers, and incentives for improved attendance should be considered [37].

The combination of inactive time - including early departures - and personal time during shifts added up to the equivalent of $6 \mathrm{~h}$ out of the 36-h work week. This reflects a substantial inefficiency in the design or delivery of health services in Lima. It is difficult to compare directly to other settings given differences in study design and health system context, but studies in Kenya and the United States have documented similar levels, with between 10 and $25 \%$ of primary care nurse and doctor time spent on personal activities [28, 38]. Additional data on productivity that were not available for this study - including patients seen and value of care provided based on clinical and patient-reported outcomes - are necessary to fully assess comparative efficiency of service delivery. Assessment of productivity could also address whether some of the personal time observed might have indirect positive effects by improving team functioning or job satisfaction. Previous research has linked longer work hours to lower satisfaction with work-life balance and found that intention to emigrate from Peru was higher among providers showing signs of burn-out 
syndrome $[39,40]$. Policies intending to enhance health system productivity in Lima should take account of the current productive time, considering the non-negligible incidence of unscheduled absenteeism and the frequency of early departures from shifts, and the uneven use of scheduled shifts for personal time.

Providers spent just under $1 \mathrm{~h}$ of each shift on direct patient care on average and $10-15 \%$ of their time on indirect care. Blocks of time with patients were generally short, approximately $3-5 \mathrm{~min}$ on average, though it is possible individual patients spanned multiple blocks. At least as much time was spent on documentation as direct and indirect care, even apart from administrative tasks, which consumed almost $10 \%$ of doctors' time in particular. While the large proportion of time on patient records is comparable to other settings [28], in this study much of the documentation and administrative tasks were paperbased rather than electronic. Computer use was most common among midwives, with two-thirds of midwives using a computer compared to half of nurses and one third of doctors, likely reflecting the initiation of EMR within maternity care services in Peru [21]. Twenty percent of the time observed on computers was in transcription to or from paper records. We found few notable differences in time allocation in providers who used computers compared to those who did not, suggesting that implementation of the system to date does not appear to be detracting from patient care, though neither is there evidence of decreased paperwork or increased productive time. As a whole these findings underscore the incomplete integration of electronic health systems into primary care services in Lima and the continued potential for efficiency gains with appropriate interventions, such as elimination of the need for transcription.

\section{Study strengths and limitations}

We drew a representative sample of urban primary care providers in a complex care environment, obtained a high response rate from providers, and collected a wealth of detail on individual use of time to assess time on productive work and the use of health information systems in practice. The study is limited by differential non-response by older, permanently tenured health care workers, and by small samples within shift types. Provider behavior may have changed due to the presence of the observer (Hawthorne effect) [41]; the results are likely to represent an upper bound for active time by providers to the extent this bias was present. Previous assessments of direct observation of clinicians have not identified substantial differences in providers' time use due to observation: providers reported that observers were quickly forgotten, and comparison of direct observation to alternative methods of recording time use have not found significant difference in categories such as personal time [27, 30, 42-44]. In studies of direct observation of provider clinical actions where a Hawthorne effect has been shown, the effect attenuated over a short time [41]. While we are not able to quantify the potential Hawthorne effect in the current data, given the length of the observations in this study and the focus on time use rather than clinical actions, we have no reason to believe provider behavior would be meaningfully altered over the full assessment. Development of the WOMBAT method in Australia included comparison across multiple studies for validation [30]; as the first application of this method in Peru, this study does not provide external validation of this method - and the categories used for application in Lima. Future efforts to confirm validity are warranted. The study and others like it in the future would be strengthened by capturing at a minimum the number of patients seen and potentially the content of care provided to enable the assessment of efficiency within the time observed.

\section{Conclusions}

If primary care is to be redefined, it is important to understand how providers use their time, their productivity, and the value of care to patients. We found that primary level care in Lima is weakened by absenteeism and non-work activities during scheduled shifts; substantial time is dedicated to paper-based record keeping and, for doctors, administrative responsibilities. The time motion study is a feasible method to address time use in settings such as Lima and can serve as key complements to population-based surveys on patient experience [23]. Future iterations that include patient data and the patient perspective would provide greater insight into efficiency and optimizing the value of primary care for patients $[45,46]$.

Interventions to improve efficiency should consider provider factors, such as dual practice in the private sector, and health system traits, such as the need for transit within facilities, the functionality of the health information system, and administrative responsibilities placed on clinicians. Particularly given the recent strain on the health system in Peru from the coronavirus pandemic, exacerbated by the aging public health care workforce, interventions must be adopted to support and revitalize the health workforce. This study provides a baseline assessment of provider time in primary care facilities in Lima and identifies substantial opportunities for improved health service delivery with the existing health workforce. 


\section{Supplementary Information}

The online version contains supplementary material available at https://doi. org/10.1186/s12913-021-06117-9.

Additional file 1: Supplemental material. Table S1. Tiers of health facilities within primary care in Lima. Figure S1. Dimensions, categories and subcategories for the observation protocol, doctors. Figure S2 Dimensions, categories and subcategories for the observation protocol, nurses and midwives. Table S2. Population of health care providers in Lima compared to all sampled providers. Figure S3. Time motion observations. Table S3. Duration of consecutive blocks of time with patients, by provider type and shift type. Table S4. Specific activities observed across providers and facility types (mean), among providers on outpatient or urgent care shifts $(N=161)$. Figure S4. Individual working time and personal time. Table S5. Proportion of time spent on direct patient care and on documentation by computer users and non-users.

\section{Abbreviations}

EMR: Electronic Medical Record; FUA: Formato Unico de Atención (Single Care Form); MOH: Ministry of Health; SD: Standard Deviation; WOMBAT: Work Observation Method By Activity Timing

\section{Acknowledgements}

The authors thank Rita Sorio at the Inter-American Development Bank, Peru, for input on study design and analysis and William Savedoff, Principal Health Specialist, Inter-American Development Bank, for critical review of the manuscript. We acknowledge the critical efforts of the study team in collecting primary data: Brenda Alcocer, Valia Cabrera, Damaris Calderón, Meyling Chong, Kiara Fiestas, Keylla Francia, Kiara Gutierrez, Norma Híjar, Dayanna Mariño, Suzzane Minaya, Laura Quispe, Jocelyn Rodríguez, Katherine Roque, and Jessica Serna. We are grateful to the clinicians who participated in the study.

\section{Authors' contributions}

Conceptualization: PJG. Methodology: PJG, HHL, DL, CC. Investigation: DL. Validation: DL. Formal analysis: DL, HHL. Resources: PJG. Data curation: DL, HHL. Writing - original draft preparation: HHL. Writing - review and editing: All. Visualization: HHL, DL. Supervision: PJG, CC, RPC. Funding acquisition: PJG. All authors have read and approved the manuscript.

\section{Funding}

This study was funded by the Inter-American Development Bank through Technical Cooperation Project RG-T3296-P001. Employees of the InterAmerican Development Bank provided input as noted in acknowledgements and authorship. Rita Sorio contributed to defining study aims and reviewed initial analysis. William Savedoff reviewed the manuscript draft. Co-author Ricardo Pérez-Cuevas provided supervision and edited the manuscript. The funding body played no other role in the design of the study and collection, analysis, and interpretation of data and in writing the manuscript.

\section{Availability of data and materials}

The protocol for the study is provided in the supplementary file. The datasets used and analysed during the current study are available from the corresponding author on reasonable request.

\section{Ethics approval and consent to participate}

The study and instruments were reviewed and approved by the IRB of Cayetano Heredia University (approval 043-04-19). Informed consent was obtained from facility directors and individual providers prior to observations commencing. Facility directors provided written consent for the facility to be included. Individual providers granted verbal informed consent as approved by the ethics committee in order to preempt provider concern that results of the observation could put them at risk.

\section{Consent for publication}

Not applicable.

\section{Competing interests}

Dr. Leslie declares research support from the Bill \& Melinda Gates Foundation, the World Bank, the World Health Organization, and ICF Macro during the course of this work. Employees of the Inter-American
Development Bank provided input as noted in acknowledgements and authorship. The funding body played no other role in the design of the study and collection, analysis, and interpretation of data and in writing the manuscript.

\section{Author details}

'Department of Global Health and Population, Harvard TH Chan School of Public Health, 677 Huntington Ave, Boston, MA, USA. ${ }^{2}$ School of Public Health, Universidad Peruana Cayetano Heredia, Lima, Peru. ${ }^{3}$ Inter-American Development Bank, Lima, Peru. ${ }^{4}$ Division of Social Protection and Health, Jamaica Country Office, Inter-American Development Bank, 6 Montrose Road, Kingston, Jamaica.

Received: 31 August 2020 Accepted: 25 January 2021

Published online: 06 February 2021

\section{References}

1. Institute of Medicine (US) Committee on Quality of Health Care in America. Crossing the Quality Chasm: A New Health System for the 21st Century. Washington (DC): National Academies Press (US); 2001. Available from: http://www.ncbi.nlm.nih.gov/books/NBK222274/. [cited 2020 Nov 25]

2. National Academies of Sciences E. Crossing the Global Quality Chasm: Improving Health Care Worldwide The National Academies Press; 2018. Available from: https://www.nap.edu/catalog/25152/crossing-the-globalquality-chasm-improving-health-care-worldwide. [cited 2020 May 28]

3. Kruk ME, Gage AD, Arsenault C, Jordan K, Leslie HH, Roder-DeWan S, et al. High-quality health systems in the sustainable development goals era: time for a revolution. Lancet Glob Health. 2018;6(11):e1196-252.

4. Starfield B, Shi L, Macinko J. Contribution of primary care to health systems and health. Milbank Q. 2005;83(3):457-502.

5. Starfield B. Primary care: an increasingly important contributor to effectiveness, equity, and efficiency of health services. SESPAS report 2012 Gac Sanit. 2012;26:20-6.

6. Kruk ME, Nigenda G, Knaul FM. Redesigning primary care to tackle the global epidemic of noncommunicable disease. Am J Public Health. 2015; 105(3):431-7.

7. Brownlee S, Chalkidou K, Doust J, Elshaug AG, Glasziou P, Heath I, et al. Evidence for overuse of medical services around the world. Lancet Lond Engl. 2017;390(10090):156-68.

8. IHME: Peru Country Profile. Institute for Health Metrics and Evaluation. 2015. Available from: http://www.healthdata.org/peru. [cited 2020 Jan 24]

9. Martin O. PAHO/WHO Data - Visualización de indicadores | OPS/OMS. Pan American Health Organization / World Health Organization. 2017. Available from: https://www.paho.org/data/index.php/es/?option=com_ content\&view=article\&id=515:indicadoresviz\&ltemid=347. [cited 2020 Aug 11]

10. Haley SJ, Terashima JP, Hoffman KA, Fuentes MSC, Wisdom JP. Barriers to primary Care in Lima, Peru. World Med Health Policy. 2017;9(2):164-85.

11. Hernández-Vásquez A, Alarcon-Ruiz CA, Díaz-Seijas D, Magallanes-Quevedo L, Rosselli D. Purchase of medications without prescription in Peru: a crosssectional population-based study. F1000Res. 2019;7. Available from: https:// www.ncbi.nlm.nih.gov/pmc/articles/PMC6364375/. [cited 2020 Jan 15]

12. Mucha T, Marilyn J. Acceso a medicamentos para controlar la hipertensión arterial prescritos en consulta externa en las Instituciones Prestadoras de Servicios de Salud (IPRESS) en Perú, ENSUSALUD 2016. Univ Peru Cayetano Heredia. 2019; Available from: http://repositorio.upch.edu.pe/handle/ upch/6611. [cited 2020 Jan 15]

13. Alarcon-Ruiz CA, Heredia P, Taype-Rondan A. Association of waiting and consultation time with patient satisfaction: secondary-data analysis of a national survey in Peruvian ambulatory care facilities. BMC Health Serv Res. 2019;19(1):439.

14. World Health Organization. Global Health Observatory Data Repository. World Health Organization. 2014. Available from: http://apps.who.int/gho/ data/view.main.52200. [cited 2015 May 18]

15. Jimenez MM, Bui AL, Mantilla E, Miranda JJ. Human resources for health in Peru: recent trends (2007-2013) in the labour market for physicians, nurses and midwives. Hum Resour Health. 2017;15. Available from: https://www. ncbi.n/m.nih.gov/pmc/articles/PMC5609041/. [cited 2020 Jan 21]

16. Registro Nacional del Personal de Salud (INFORHUS). Lima, Peru: Ministry of Health; 2019. Available from: http://inforhus.minsa.gob.pe/login.php. [cited 2019 May 15] 
17. Hsieh EJ, Blas MM, La Rosa RS, Garcia PJ. Sexually transmitted infections and private physicians in Peru, 2003. Rev Panam Salud Publica. 2006;20(4):223-9.

18. SUSALUD. Registro Nacional de IPRES. Available from: http://app20.susalud. gob.pe:8080/registro-renipress-webapp/listadoEstablecimientosRegistrados htm?action=mostrarBuscar\#no-back-button. [cited 2019 Dec 20]

19. Mendoza-Arana P, Río G, Gutiérrez-Villafuerte C, Sanabria-Montáñez C. The process of health sector reform in Peru Processo de reforma da saúde no Peru. Rev Panam Salud Pública. 2018;42(e74) Available from: https:// europepmc.org/article/med/31093102. [cited 2020 Jan 21].

20. Velásquez A, Suarez D, Nepo-Linares E. Health sector reform in Peru: law, governance, universal coverage, and responses to health risks. Rev Peru Med Exp Salud Publica. 2016;33(3):546-55

21. Pérez-Lu JE, Iguiñiz Romero R, Bayer AM, García PJ. Reduciendo las inequidades en salud y mejorando la salud materna mediante la mejora de los sistemas de información en salud: Wawared Perú. Rev Peru Med Exp Salud Pública. 2015;32(2):373.

22. Beuermann DW, Garcia P, Lu JP, Anta R, Maffioli A, Rodrigo MF. Information and communication technologies, prenatal care services, and neonatal health. J Econ Race Policy. 2020;3(1):41-59.

23. Guanais F, Doubova SV, Leslie HH, Perez-Cuevas R, García-Elorrio E, Kruk ME. Patient-centered primary care and self-rated health in 6 Latin American and Caribbean countries: analysis of a public opinion cross-sectional survey. Plos Med. 2018;15(10):e1002673.

24. Carbajal Morelos C, Laos Carbajal D. Crowding-in physician motivation: aligning incentives in public hospitals in Peru. 2017. (Second year paper).

25. Lopetegui M, Yen P-Y, Lai A, Jeffries J, Embi P, Payne P. Time motion studies in healthcare: what are we talking about? J Biomed Inform. 2014;0:292-9.

26. Zheng K, Guo MH, Hanauer DA. Using the time and motion method to study clinical work processes and workflow: methodological inconsistencies and a call for standardized research. J Am Med Inform Assoc. 2011;18(5): 704-10.

27. Westbrook Jl, Duffield C, Li L, Creswick NJ. How much time do nurses have for patients? A longitudinal study quantifying hospital nurses' patterns of task time distribution and interactions with health professionals. BMC Health Serv Res. 2011;11(1):319.

28. Pizziferri L, Kittler AF, Volk LA, Honour MM, Gupta S, Wang S, et al. Primary care physician time utilization before and after implementation of an electronic health record: a time-motion study. J Biomed Inform. 2005;38(3):176-88.

29. Schenk E, Schleyer R, Jones CR, Fincham S, Daratha KB, Monsen KA. Time motion analysis of nursing work in ICU, telemetry and medical-surgical units. J Nurs Manag. 2017;25(8):640-6.

30. Ballermann MA, Shaw NT, Mayes DC, Gibney RN, Westbrook Jl. Validation of the work observation method by activity timing (WOMBAT) method of conducting time-motion observations in critical care settings: an observational study. BMC Med Inform Decis Mak. 2011;11(1):32.

31. Westbrook Jl, Li L, Shah S, Lehnbom EC, Prgomet M, Schofield B, et al. A cross-country time and motion study to measure the impact of electronic medication management systems on the work of hospital pharmacists in Australia and England. Int J Med Inf. 2019;129:253-9.

32. Li L, Hains I, Hordern T, Milliss D, Raper R, Westbrook J. What do ICU doctors do?: a multisite time and motion study of the clinical work patterns of registrars. Crit Care Resusc. 2015;17(3):159.

33. Belita A, Mbindyo P, English M. Absenteeism amongst health workers developing a typology to support empiric work in low-income countries and characterizing reported associations. Hum Resour Health. 2013;11(1):34.

34. Chaudhury N, Hammer J, Kremer M, Muralidharan K, Rogers FH. Missing in action: teacher and health worker absence in developing countries. J Econ Perspect. 2006;20(1):91-116.

35. Jumpa M, Jan S, Mills $A$. The role of regulation in influencing incomegenerating activities among public sector doctors in Peru. Hum Resour Health. 2007:5(1):5

36. LaGrone LN, Isquith-Dicker LN, Egoavil EH, Herrera-Matta JJ, Fuhs AK, Checa DO, et al. Surgery and trauma care providers' perception of the impact of dual-practice employment on quality of care provided in an Andean country. Br J Surg. 2017;104(6):704-9.

37. Kisakye AN, Tweheyo R, Ssengooba F, Pariyo GW, Rutebemberwa E, Kiwanuka SN. Regulatory mechanisms for absenteeism in the health sector: a systematic review of strategies and their implementation. J Healthc Leadersh. 2016;8:81-94.

38. Tierney WM, Sidle JE, Diero LO, Sudoi A, Kiplagat J, Macharia S, et al. Assessing the impact of a primary care electronic medical record system in three Kenyan rural health centers. J Am Med Inform Assoc. 2016;23(3):544-52

39. Valentina Rocío Muñoz Araya. Insatisfacción de balance trabajo-vida en médicos y enfermeras de establecimientos de salud de Perú, ENSUSALUD 2016. [Lima, Peru]: Universidad Peruana de Ciencias Aplicadas; 2018. Available from: https://repositorioacademico.upc.edu.pe/handle/10757/624968. [cited 2020 Jan 15]

40. Anduaga-Beramendi A, Beas R, Maticorena-Quevedo J, Mayta-Tristán P. Association between burnout and intention to emigrate in Peruvian healthcare workers. Saf Health Work. 2019;10(1):80-6.

41. Leonard K, Masatu MC. Outpatient process quality evaluation and the Hawthorne effect. Soc Sci Med. 2006;63(9):2330-40.

42. Ampt A, Westbrook J, Creswick N, Mallock N. A comparison of self-reported and observational work sampling techniques for measuring time in nursing tasks. J Health Serv Res Policy. 2007;12(1):18-24.

43. Schnelle JF, Ouslander JG, Simmons SF. Direct observations of nursing home care quality: does care change when observed? J Am Med Dir Assoc. 2006;7(9):541-4.

44. Dean B, Barber N. Validity and reliability of observational methods for studying medication administration errors. Am J Health Syst Pharm. 2001; 58(1):54-9.

45. Doubova SV, Ramírez-Sánchez C, Figueroa-Lara A, Pérez-Cuevas R. Recursos humanos para la atención de pacientes con diabetes en unidades de medicina familiar del Instituto Mexicano del Seguro Social. Salud Pública México. 2013;55(6):607-17.

46. Meyers D, LeRoy L, Bailit M, Schaefer J, Wagner E, Zhan C. Workforce configurations to provide high-quality, comprehensive primary care: a mixed-method exploration of staffing for four types of primary care practices. J Gen Intern Med. 2018;33(10):1774-9.

\section{Publisher's Note}

Springer Nature remains neutral with regard to jurisdictional claims in published maps and institutional affiliations.

\section{Ready to submit your research? Choose BMC and benefit from:}

- fast, convenient online submission

- thorough peer review by experienced researchers in your field

- rapid publication on acceptance

- support for research data, including large and complex data types

- gold Open Access which fosters wider collaboration and increased citations

- maximum visibility for your research: over $100 \mathrm{M}$ website views per year

At $\mathrm{BMC}$, research is always in progress.

Learn more biomedcentral.com/submissions 